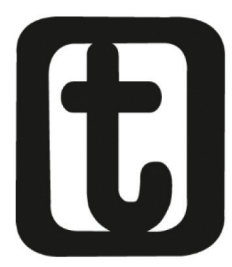

\title{
DESENVOLVIMENTO E IGUALDADE DE GÊNERO: AVANÇOS E DESAFIOS NO ENFRENTAMENTO DA VIOLÊNCIA CONTRA A MULHER
}

Development and gender equality: advances and challenges in fighting violence against women

\author{
Patrícia Krieger Grossi' \\ Jaqueline Goulart Vincensi ${ }^{2}$ \\ Sônia Maria A. F Almeida ${ }^{3}$ \\ Jaina Raqueli Pedersen ${ }^{4}$
}

\section{RESUMO}

Este artigo tem por objetivo destacar a importância de políticas públicas de enfrentamento à violência contra a mulher e da Lei Maria da Penha, a partir do olhar dos gestores das políticas de assistência social, coordenadores das Políticas de Mulheres e profissionais que atuam em Centros de Referência de Mulheres, Centros de Referência de Assistência Social (Cras) e Centro de

\footnotetext{
${ }^{1}$ Assistente Social. Professora do Programa de Pós-graduação em Serviço Social da Pontifícia Universidade Católica do Rio Grande do Sul - PUCRS . Doutora em Serviço Social, PhD Universidade de Toronto, Canadá. Pós doutorado na Univ. de Toronto. Coordenadora do Grupo de Estudos e Pesquisa em Violência (NEPEVI-PUCRS). Email: <pkgrossi@pucrs.br >.

2 Assistente Social. Mestre em Serviço Social pela PUCRS. Pesquisadora colaboradora do Grupo de Estudos e Pesquisa em Violência (NEPEVI-PUCRS). E-mail: <linevincensi@hotmail.com>.

3 Assistente Social. Doutora em Serviço Social pela PUCRS. Professora da Faculdade de Serviço Social da Universidade do Vale dos Sinos (UNISINOS). Email: <soniaa@unisinos.br>.

4 Assistente Social. Mestre em Serviço Social. Doutoranda em Serviço Social na PUCRS. Docente do Curso de Serviço Social da Universidade Federal do Pampa (UNIPAMPA). Email: <jainaraqueli@bol.com.br>.
} 
Referência Especializado da Assistência Social (Creas) e mulheres em atendimento em municípios do Estado do Rio Grande do Sul. As entrevistas com os profissionais e gestores foram gravadas, bem como as do grupo focal com as mulheres, transcritas e posteriormente submetidas à análise de conteúdo de Bardin. Os dados apontam para a existência de uma rede de proteção que necessita ser ampliada e articulada intersetorialmente com outras políticas para atendimento das necessidades das mulheres, além de maior conhecimento da Lei Maria da Penha como instrumento de garantia de direitos das mulheres.

\section{PALAVRAS-CHAVE}

Violência contra a mulher. Rede social. Lei Maria da Penha.

\section{ABSTRACT}

This article has the objective of highlighting the importance of public policies for the prevention of violence against women from the perspective of managers of the social welfare policies, coordinators of women's policies, professionals that work in Reference Centers for Women, Reference Centers of Social Welfare (Cras) and Specialized Reference Center of Social Welfare (Creas) and women who were service users in municipalities of the State of Rio Grande do Sul. The interviews with professionals and managers were tape-recorded as well as the focus groups with women, transcribed and submitted to content analysis of Bardin afterwards. The data points out that there is a network of services for protection of women that needs to be enlarged and better articulated with other social policies to meet their needs. In addition, there is a need of more knowledge about the Maria da Penha Law as a tool for the women's guarantee of rights.

\section{KEYWORDS}

Violence against women. Social network. Maria da Penha Law. 


\section{INTRODUÇÃO}

Estudos e pesquisas encomendados pelo Ministério da Saúde brasileiro e pela Organização das Nações Unidas (ONU) apontam que a violência contra a mulher atinge milhares de brasileiras, independentemente de idade, etnia e classe social, além de a maioria dos casos ocorrerem dentro do próprio lar, tendo o cônjuge/companheiro como o agressor. Estima-se, segundo a Pesquisa Perseu Abramo (2010), que a cada 15 segundos uma mulher é violentada no Brasil e o custo dessa violência é de 10,5\% do PIB. A violência doméstica contra a mulher é uma das formas de violação de direitos humanos mais praticadas e menos reconhecidas no mundo, produzindo danos físicos, emocionais e patrimoniais. Essa é uma expressão grave das desigualdades em que vivem as pessoas do sexo feminino, o que atravessa gerações. Não podemos falar em desenvolvimento pleno de uma sociedade quando a maioria da população sofre discriminações de gênero, raça/etnia, classe social, entre outras.

Como resposta a essa situação de violência de gênero, o Brasil vive um tempo de afirmação das políticas públicas, com a adoção de sistemas institucionais que apresentam, nos últimos anos, níveis crescentes de integração, envolvendo as três esferas de governo - a União, os Estados e os Municípios -, e de democratização, com o fortalecimento do controle social, através das conferências, dos conselhos e da participação popular direta. Como resultado, observa-se a concepção, por parte do Estado e da sociedade civil, de diferentes estratégias para a erradicação da violência doméstica contra a mulher, como a recente criação da Secretaria Estadual da Mulher no Rio Grande do Sul.

O presente artigo tem por objetivo principal verificar os avanços e desafios da Lei Maria da Penha na implementação das políticas de enfrentamento à violência doméstica contra a mulher no Estado do Rio Grande do Sul, a partir da visibilidade das falas das mulheres em situação de violência doméstica e dos profissionais da rede de serviços. 


\section{CONCEITUANDO VIOLÊNCIA DOMÉSTICA CONTRA MULHER NO ÂMBITO DA LEI MARIA DA PENHA}

No que se refere à violência doméstica e familiar praticada contra a mulher, a Lei Maria da Penha (BRASIL, 2006) a caracteriza por qualquer ação ou omissão baseada no gênero que lhe cause morte, lesão, sofrimento físico, sexual ou psicológico e dano moral ou patrimonial:

I - no âmbito da unidade doméstica, compreendida como o espaço de convívio permanente de pessoas, com ou sem vínculo familiar, inclusive as esporadicamente agregadas;

II - no âmbito da família, compreendida como a comunidade formada por indivíduos que são ou se consideram aparentados, unidos por laços naturais, por afinidade ou por vontade expressa;

III - em qualquer relação íntima de afeto, na qual o agressor conviva ou tenha convivido com a ofendida, independentemente de coabitação (BRASIL, 2006, Art. $5^{\circ}$ ).

Dentre as formas de violência doméstica e familiar contra a muIher, a Lei Maria da Penha ressalta as seguintes:

I - a violência física, entendida como qualquer conduta que ofenda sua integridade ou saúde corporal;

II - a violência psicológica, entendida como qualquer conduta que lhe cause dano emocional e diminuição da auto-estima ou que lhe prejudique e perturbe o pleno desenvolvimento ou que vise degradar ou controlar suas ações, comportamentos, crenças e decisões, mediante ameaça, constrangimento, humilhação, manipulação, isolamento, vigilância constante, perseguição contumaz, insulto, chantagem, ridicularização, exploração e limitação do direito de ir e vir ou qualquer outro meio que Ihe cause prejuízo à saúde psicológica e à autodeterminação;

III - a violência sexual, entendida como qualquer conduta que a constranja a presenciar, a manter ou a participar de relação sexual não desejada, mediante intimidação, ameaça, coação ou uso da 
força; que a induza a comercializar ou a utilizar, de qualquer modo, a sua sexualidade, que a impeça de usar qualquer método contraceptivo ou que a force ao matrimônio, à gravidez, ao aborto ou à prostituição, mediante coação, chantagem, suborno ou manipulação; ou que limite ou anule o exercício de seus direitos sexuais e reprodutivos;

IV - a violência patrimonial, entendida como qualquer conduta que configure retenção, subtração, destruição parcial ou total de seus objetos, instrumentos de trabalho, documentos pessoais, bens, valores e direitos ou recursos econômicos, incluindo os destinados a satisfazer suas necessidades;

V - a violência moral, entendida como qualquer conduta que configure calúnia, difamação ou injúria (BRASIL, 2006, Art. $7^{\circ}$ ).

Ressalta-se que muitas mulheres sofrem todos esses tipos de violência ao mesmo tempo, constituindo-se uma das principais formas de violação dos seus direitos humanos, atingindo-as em seus direitos à vida, à saúde e à integridade física. A violência contra a mulher também acaba trazendo vários prejuízos para as crianças que com ela convivem, pois, como destaca Perry (apud STREY, 2004, p. 31), presenciar a violência doméstica, como o espancamento da mãe, pode ser igualmente, ou até mais traumático para as crianças e, assim, mais traumático para o desenvolvimento saudável do cérebro do que outros eventos traumáticos.

A violência doméstica e familiar é um fenômeno que atinge muIheres de diferentes classes sociais, origens, regiões, estados civis, escolaridade e etnias. Ainda que seja um fenômeno reconhecidamente presente na vida de milhões de brasileiras, não existem estatísticas sistemáticas e oficiais que apontem a magnitude desse fenômeno. Desse modo, é preciso destacar que o enfrentamento e a prevenção da violência contras as mulheres, bem como dos demais membros que compõem o grupo familiar, implicam a promoção de conhecimento sobre esse fenômeno e a percepção social de que a violência doméstica e familiar e também a maior vulnerabilidade de mulheres e meninas ao tráfico e à exploração sexual são problemas da maior gravidade. 
Diante dessas diferentes conformações da violência, o que se evidencia é a necessidade de implementação de políticas públicas amplas e articuladas nas diversas esferas da vida social, como na educação, no mundo do trabalho, na saúde, na segurança pública, na assistência social, entre outras previstas na Lei. Essa conjunção de esforços deve resultar em ações que, simultaneamente, desconstruam as desigualdades e combatam as discriminações de gênero, interfiram nos padrões sexistas/ machistas ainda presentes na sociedade brasileira e promovam o empoderamento das mulheres. Trata-se, portanto, de enfrentar não apenas a dimensão do combate aos efeitos da violência contra as mulheres, mas também as dimensões da prevenção, atenção, proteção e garantia dos direitos de mulheres.

Compreende-se que a violência doméstica contra a mulher é fruto de uma construção social que demarca espaços de poder, privilegiando os homens e oprimindo as mulheres. Constitui-se, conforme Saffioti (1997, p. 8), “[...] numa violação aos direitos humanos e um obstáculo para a cidadania de milhares de muIheres". A violência marca profundamente o corpo e os espaços psíquicos da mulher, tendo graves consequências, tanto na sua sociabilidade (isolamento, fragilização das redes de pertencimento) como para a sua saúde física (lesões corporais leves e graves, transtornos gastrointestinais), psicológica (depressão, ansiedade, tentativa de suicídio) e sexual (doenças sexualmente transmissíveis) (SAFIOTTI, 1997).

\section{VIOLÊNCIA DE GÊNERO E DESENVOLVIMENTO: A IMPOR- TÂNCIA DE POLÍTICAS TRANSVERSAIS DE GÊNERO}

Além da violência doméstica, existem outras formas de violência de gênero, que são identificadas através de um indicador chamado Índice de Desenvolvimento de Gênero (IDG). Esse indicador, adotado desde 1995 pelo Programa das Nações Unidas para o Desenvolvimento, avalia as diferenças de desenvolvimento humano entre homens e mulheres nas seguintes dimensões e variáveis: uma vida longa e saudável, medida pela esperança de vida à nascença; o conhecimento, traduzido pelas taxas de alfabetização de adultos e de escolarização bruta; e um nível 
de vida digno, avaliado pelo rendimento auferido estimado. 0 índice de desenvolvimento ajustado ao gênero, embora se baseie nos mesmos indicadores que o Índice de Desenvolvimento Humano (IDH), leva em consideração a desigualdade entre os sexos: quanto maior for a desigualdade, maior será a diferença entre o IDG e o IDH. Normalmente, as grandes discrepâncias entre os dois indicadores são o reflexo da diferença de rendimentos entre homens e mulheres.

Nesse sentido, em um ranking composto por 146 países, o Brasil ocupa a $80^{a}$ posição, com IDG de 0,449, atrás de nações como Chile, Argentina, Peru, México, Venezuela, Líbia, Líbano e Kuwait.

Segundo o relatório do Programa das Nações Unidas para o Desenvolvimento (PNUD), de 2002, em comparação com os homens, um percentual maior de mulheres tem alcançado pelo menos 0 nível de educação secundária - 48,8\% delas, contra 46,3\% deles. Apesar disso, a taxa de participação feminina no mercado de trabalho é de $60,1 \%$, enquanto a masculina é de $81,9 \%$ (PNUD, 2002).

Outro traço marcante na desigualdade de gênero percebida no Brasil é o fato de apenas 9,6\% dos assentos do Congresso Nacional serem ocupados por mulheres.

Frente a essas desigualdades de gênero, o II Plano Nacional de Políticas para Mulheres prevê diversos programas e medidas nos seguintes eixos (BRASIL, 2010):

- Autonomia econômica e igualdade no mundo do trabalho;

- Educação inclusiva;

- Saúde das mulheres, direitos sexuais e reprodutivos;

- Enfrentamento de todas as formas de violência contra as mulheres (incluindo prostituição e tráfico);

- Participação das mulheres nos espaços de poder e decisão;

- Desenvolvimento sustentável com justiça ambiental, soberania e segurança alimentar;

- Direito a terra, moradia digna e infraestrutura, considerando as comunidades tradicionais; 
- Cultura, comunicação e mídia igualitárias, democráticas e não discriminatórias;

- Enfrentamento do racismo, sexismo e lesbofobia;

- Enfrentamento das desigualdades geracionais que atingem as mulheres, com especial atenção às jovens e idosas;

- Gestão e monitoramento do plano do governo.

Essas medidas requerem políticas transversais de gênero. A noção de transversalidade de gênero - ou gender mainstreaming - surgiu dos movimentos feministas internacionais, os quais constataram que as mudanças em relação à situação das mulheres no mundo têm sido pouco expressivas. Essa proposta prevê políticas transversais a todas as áreas e níveis de governo, atuando como estímulo para reformar e modernizar o aparelho estatal, além de incorporar aportes da sociedade civil na definição, execução e avaliação das ações junto às mulheres.

Contemporaneamente, entende-se que enfrentar a violência contra as mulheres requer não só uma percepção multidimensional do fenômeno como também a convicção de que, para superá-la, é preciso investir no desenvolvimento de políticas que acelerem a redução das desigualdades entre homens e mulheres. Em nível mundial, são inegáveis os avanços que asseguram cada vez mais direitos às mulheres, através de uma perspectiva de transversalidade de gênero. No Rio Grande do Sul, foi criado recentemente o Comitê Transversal de Gênero para implementar políticas transversais de gênero, a fim de avançarmos na garantia da igualdade de gênero.

A Secretaria de Políticas para as Mulheres (SPM) logrou introduzir em alguns órgãos do governo federal a discussão a respeito da desigualdade entre homens e mulheres e sua relação com o desenho, a implementação e a avaliação das políticas públicas. $O$ papel do governo federal no enfrentamento dessas desigualdades foi traduzido em ações diversificadas e plurais, executadas por órgãos que atuam sobre os diferentes aspectos da vida em sociedade. Nesse sentido, muitos avanços foram alcançados, mas ainda há um longo caminho a ser percorrido. As áreas que incorporaram a perspectiva de gênero precisam ainda avançar para a consolidação de suas ações e desenvolver estratégias para lhes 
conferir maior visibilidade em sua programação e orçamento. Essas necessidades reforçam-se diante do atual contexto de continuidade no governo federal e, o mais importante, com a elaboração de um novo Plano Plurianual e de revisão do Plano Nacional de Políticas para as Mulheres. A incorporação da perspectiva de gênero nos processos de planejamento dos planos plurianuais não somente pela Secretaria de Política para as Mulheres, mas para os demais órgãos do governo federal, apresenta-se como uma oportunidade importante para aperfeiçoar a inserção desse recorte nas políticas do governo federal (IPEA, 2007).

Além da transversalidade de gênero, outros elementos essenciais são a interdisciplinaridade e a intersetorialidade na criação de serviços especializados dentro da estruturação da Política Nacional de Enfrentamento à Violência contra as Mulheres. Trabalhar esses princípios pressupõe o desenvolvimento de uma articulação em rede:

$\mathrm{O}$ conceito de Rede de atendimento refere-se à atuação articulada entre as instituições/serviços governamentais, não-governamentais e a comunidade, visando à ampliação e melhoria da qualidade do atendimento; identificação e encaminhamento adequado das mulheres em situação de violência; e ao desenvolvimento de estratégias efetivas de prevenção. A constituição da rede de atendimento busca dar conta da complexidade da violência contra as mulheres e do caráter multidimensional do problema, que perpassa diversas áreas, tais como: a saúde, a educação, a segurança pública, a assistência social, a cultura, entre outros (BRASIL, 2005, p. 14).

No item a seguir, apresentaremos alguns dados da pesquisa realizada sobre os avanços e desafios da Lei Maria da Penha na implementação de políticas públicas de enfrentamento à violência contra as mulheres.

\section{RESULTADOS DA PESQUISA}

A rede de atendimento às mulheres em situação de violência doméstica no Estado do Rio Grande do Sul é composta por 19 Centros de Referência à Mulher, 9 casas-abrigos, delegacias espe- 
cializadas à mulher, serviços de assistência jurídica gratuita (como Jus-Mulher, Saju-UFRGS, Sajug-PUCRS), Defensoria Pública com Núcleos Especializados para atendimento de mulheres, Centros de Referência Especializado da Assistência Social (Creas), Hospitais com serviços de prevenção à violência, além de outros espaços, como o trabalho desenvolvido em Organizações não Governamentais (ONGs) feministas, como Maria Mulher, Ilê Mulher, Associação Cultural de Mulheres Negras, etc. Contudo, os serviços da rede de proteção apresentam problemas em relação ao funcionamento em termos de horário, conforme consta no depoimento da delegada de Porto Alegre, no relatório do Observatório da Lei Maria da Penha (2009). E sua fala se contradiz com as falas dos profissionais que reconhecem a existência de uma rede de serviços para atendimento da mulher em situação de violência doméstica:

A coordenadoria se tornou um centro de referência para as mulheres, depois que elas descobriram o caminho da delegacia, descobriram a rede [...] hoje nós temos os Cras e o Creas [...] esses equipamentos, eles estão a serviço das mulheres ( $\left.\mathrm{P}_{1}, \mathrm{M}_{5}\right)$.

Bom, a rede de serviços é: o Centro de Referência a Vítima de Violência, o Centro de Referência da MuIher. A maioria das mulheres procura a Delegacia da Mulher para fazer a ocorrência, para registrar a ocorrência, Defensoria Pública para ajuizar a ação, para ajuizar o processo [...]. Quando a mulher necessita de abrigagem, nós contatamos com os dois abrigos que existem [...] um dos abrigos é exclusivo para as mulheres vítimas de violência $\left(P_{1}, M_{3}\right)$.

Nós temos o Cras móvel, que é um equipamento móvel que circula pelas comunidades, agora nós temos uma delegacia da mulher móvel que também vai começar a ser itinerante para que as mulheres que tem dificuldades de virem até o centro, possam estar acessando esses serviços ( $\left.\mathrm{P}_{1}, \mathrm{M}_{5}\right)$.

Um dos desafios para o avanço na garantia da proteção das muIheres vítimas de violência doméstica é levar o conhecimento dos direitos assegurados na legislação, como a Lei 11.340, de 2006, mais conhecida como Lei Maria da Penha (BRASIL, 2006). A partir da realização de grupos focais com mulheres de diferen- 
tes municípios do Rio Grande do Sul em atendimento na rede de proteção, verificou-se que o conhecimento e a percepção a respeito da Lei diferem em relação à sua aplicabilidade:

Essa Lei Maria da Penha foi um, um respeito [...] eu achei ótima, muito boa, acho que se eu não tivesse colocado ele lá e não tivesse essa Lei eu já tava morta (G4, M2).

Eu conheço (Lei Maria da Penha), não acho que ela funcione, é muito fraca, mas todas (legislações) têm uma brecha $\left(G_{1}, M_{7}\right)$.

Ta na hora de ver a lei do agressor que tem que ser punido [...] Eles têm que procurar uma ajuda psicológica também (G3, M8).

Por enquanto pra mim ela foi extremamente eficiente, em 2 dias eu voltei pra minha casa $(G 4, M 8)$.

Ele [marido] ficou 5 horas preso. Tu nunca vai ter a certeza de tá tranquila; chega em casa sempre com aquela insegurança. Se eu tirar a queixa, ele não vai fazer nada, se eu não retirar, ele vai tentar alguma coisa (G4, M8).

Eles [agressores] continuam com a vida normal deles, nós [vítimas] não, nós estamos abaladas psicologicamente, nós nos prejudicamos no trabalho porque o nosso rendimento baixa, nossas relações baixam, nossa vida dá uma guinada daquelas, tu para de estudar [...] tem situações e situações, a tua vida tem um baque e a deles não $(G 4, M 8)$.

A violência, sutil ou declarada, como marca constante nas relações interpessoais e sociais, reflete-se na qualidade de vida, nos sentimentos e nas imposições culturais das e entre as pessoas envolvidas. É a negação permanente dos Direitos Humanos e a banalização da violência e do sofrimento das pessoas, cuja materialidade impossibilita, de maneira velada ou não, reflexões e críticas, tendo como consequência a indiferença e o abandono de quem sofre situações de violência.

Mesmo com a existência da Lei Maria da Penha, que foi considerada um avanço frente à lei anterior - que banalizava a violência contra a mulher ao considerá-la como crime de menor potencial 
ofensivo, cabendo ao réu a prestação de serviços à comunidade ou o pagamento de uma cesta básica -, a insegurança permeia o cotidiano dessas mulheres. É possível garantir a segurança da mulher com uma medida protetiva? Há, também, necessidade de programas de reabilitação para homens agressores, para que estes possam se responsabilizar frente ao ocorrido e pensar novas formas de relações sociais baseadas em uma igualdade de gênero.

Se o exercício da cidadania, o direito a ter direitos, é negado pela violência, tem-se, consequentemente, a negação do sujeito de direitos, questão fundamental em casos de violência doméstica na esfera familiar. Isso afeta todo um sistema de proteção, exigindo das políticas públicas um novo olhar para esse fenômeno, não só conceitualmente como também na ação dos agentes nos espaços socioinstitucionais. Ao não serem consideradas as diferentes expressões de violência vivenciadas por essas mulheres (desde a violência institucional, estrutural e simbólica, que gera agravos à saúde mental), o ciclo de vitimização se perpetua. Romper com o ciclo de exclusão, que resulta no fenômeno da feminização da pobreza, é o primeiro passo para superar processos de subaltenização da mulher na sociedade, através de programas voltados para a promoção de sua autonomia financeira. A mera punição do agressor com encarceramento e a medida protetiva de afastamento do agressor não garantirão o rompimento com a situação de violência.

Para promover uma sociedade baseada na igualdade de gênero, práticas emancipatórias se tornam necessárias. O empoderamento de mulheres pode ser definido como:

Um processo de reconhecimento, criação e utilização de recursos e de instrumentos pelos indivíduos, grupos e comunidades, em si mesmos e no meio envolvente, que se traduz num acréscimo de poder - psicológico, sócio-cultural, político e econômico que permite a estes sujeitos aumentar a eficácia do exercício da sua cidadania (PINTO, 1988, p. 247).

É necessário afirmar que o objetivo do empoderamento é fortalecer em direitos e em participação populações, pessoas ou grupos sujeitos a discriminação e exclusão e, até mesmo, fiscalizar 
os poderes estatais e os grandes interesses econômicos, numa luta permanente contra a opressão. Pretende favorecer a efetiva participação dos cidadãos na vida social, econômica, política e cultural, e uma distribuição mais equitativa dos recursos.

No entanto, percebe-se que a via da intersetorialidade nas políticas públicas não ocorre espontaneamente, pois não é algo natural. É uma construção compartilhada, que necessita de mudanças nos processos técnico-operativos, de gestão e de planejamento, sendo, sobretudo, uma determinação política. Uma pesquisa realizada pelo Observatório Lei Maria da Penha (2011), em Porto Alegre, verificou que a articulação da rede de proteção à mulher não ocorre espontaneamente, pois quem determinou um Fórum para as entidades foi o Juiz da Vara Especializada de Violência contra a Mulher, conforme está descrito nas conclusões do relatório:

Outra iniciativa que parece provocar algum desconforto entre a(o)s entrevistada(o)s é a convocatória feita pelo juiz, para a criação de um Fórum de Enfrentamento à Violência Doméstica. Ainda que esta iniciativa tenha provocado a participação dos diferentes setores - serviços, ONGs e movimento de mulheres - e todos venham participando e discutindo os obstáculos para a implementação da Lei Maria da Penha e para articulação da rede no município, foram também colocadas reflexões sobre qual o papel que o Judiciário deve ter nesta articulação (OBSERVATÓRIO LEI MARIA DA PENHA, 2011, p. 45).

Embora a intersetorialidade em políticas públicas seja algo recente, já está sendo considerada como uma alternativa de resolução de problemas com a qual a gestão pública pode contar para alcançar maior efetividade e impacto sobre os problemas e demandas da população, com uma visão integrada dessas questões e de suas soluções. Outra perspectiva é o trabalho interdisciplinar, pois este rompe com as fronteiras do conhecimento e permite compreender a mulher na sua integralidade. Compartilhamos a posição de Lück (2002) da necessidade do enfoque interdisciplinar tanto no estudo como na intervenção:

O enfoque interdisciplinar consiste num esforço de busca global da realidade, como superação das im- 
pressões estáticas, e do hábito de pensar fragmentador e simplificador da realidade. Ele responde a uma necessidade de transcender a visão mecanicista e linear e estabelecer uma ótica globalizadora que vê a realidade, em seu movimento, constituída por uma teia dinâmica de inter-relações circulares, visando estabelecer o sentido de unidade que ultrapassa as impressões fracionadas e o hábito de pensar e de exprimir-se por pares e opostos, como condição e resultado final do processo de produção do conhecimento (LÜCK, 2002, p. 72).

A velocidade das mudanças exige práticas interdisciplinares de pesquisa para que possamos fazer uma leitura dialética da realidade, que é múltipla e una, ao mesmo tempo. Conquanto um problema de pesquisa possa ser delimitado, as múltiplas determinações históricas e sociais que o constituem não podem ser ignoradas, principalmente em se tratando do tema violência de gênero e desenvolvimento - este que por si só é um termo polissêmico, com múltiplos significados e interpretações. Para avançarmos no desenvolvimento de uma sociedade, precisamos dar vozes aos sujeitos da pesquisa, levar o conhecimento produzido na academia para as comunidades, para o poder público, servindo de subsídios para a reflexão e ação, e uma qualificação das políticas e práticas de enfrentamento às múltiplas expressões de violência contra a mulher.

\section{CONCLUSÕES}

As narrativas presentes neste artigo revelam os desafios na articulação da rede de serviços de proteção à mulher em situação de violência doméstica a partir da perspectiva dos gestores das políticas de assistência social, coordenadores das Políticas de Mulheres e profissionais que atuam em Centros de Referência de Mulheres, Centros de Referência de Assistência Social (Cras) e Centro de Referência Especializado da Assistência Social (Creas), vinculados ao Programa de Atenção Especializado a Famílias e Indivíduos (Paefi) nos municípios do Estado do Rio Grande do Sul. Participaram desta pesquisa os municípios de Carazinho, Selbach, Caxias do Sul, Arroio do Tigre, Passo Fundo, Charquea- 
das, São Leopoldo, Canoas, Novo Hamburgo e Porto Alegre. Os dados apresentados refletem os resultados parciais da pesquisa Avanços e desafios da Lei Maria da Penha na implementação de políticas públicas de enfrentamento à violência contra a mulher no Estado do RS, apoiada pelo Conselho Nacional de Desenvolvimento Científico e Tecnológico (CNPq) e aprovada pelo Comitê de Ética em Pesquisa da Pontifícia Universidade Católica do Rio Grande do Sul (PUCRS).

Entre os desafios está a materialização dos pressupostos de trabalho em rede, como a horizontalidade e o enfrentamento das relações de poder existentes entre diferentes políticas e setores. Como possibilidade, destaca-se a articulação de profissionais de diferentes áreas de saber no atendimento à complexidade das demandas trazidas por mulheres em situação de violência doméstica.

Torna-se fundamental visibilizar o Serviço Social, nesta área de atuação, mesmo que o objeto do presente estudo seja interdisciplinar. Ao se falar em direitos humanos, em fortalecimento das políticas públicas e no protagonismo das mulheres, está-se no campo de atuação, especialmente, ético-político do Serviço Social. Para tal, retoma-se a discussão, mesmo que brevemente, sobre o projeto ético-político do Serviço Social, o qual se centraliza na perspectiva dos direitos. Assim, intervir profissionalmente em processos sociais e institucionais no enfrentamento da violência doméstica significa materializar a ética que compromete assistentes sociais na luta por direitos sociais, na perspectiva de uma sociedade emancipada, portanto, com sujeitos livres e autônomos.

Sabe-se que, no contexto atual, estrutural e conjuntural, esse compromisso representa um grande desafio. No entanto, enfrentá-lo requer, por parte dos assistentes sociais, permanente resistência contra a banalização da violência, contra a barbarização da vida social e interpessoal, e exige, ao mesmo tempo, capacitação continuada. Nesse aspecto, tratando-se de um campo de atuação, cuja perspectiva é a de gênero, pensa-se como fundamental privilegiar esta categoria na formação e no exercício profissional. Efetivar essa vinculação significa estratégia cen- 
tral na concretização do projeto ético-político do Serviço Social rumo a uma sociedade mais justa e igualitária. Somente assim poderemos falar em desenvolvimento.

\section{REFERÊNCIAS}

BRASIL. Lei n. 11.340, de 7 de agosto de 2006. Cria mecanismos para coibir a violência doméstica e familiar contra a mulher, nos termos do § 80 do art. 226 da Constituição Federal, da Convenção sobre a Eliminação de Todas as Formas de Discriminação contra as Mulheres e da Convenção Interamericana para Prevenir, Punir e Erradicar a Violência contra a Mulher; dispõe sobre a criação dos Juizados de Violência Doméstica e Familiar contra a Mulher; altera o Código de Processo Penal, o Código Penal e a Lei de Execução Penal; e dá outras providências. Disponível em: <http://www.planalto.gov.br/CCIVIL/Ato2004-2006/2006/ Lei/L11340.htm>. Acesso em: 2 jul. 2008.

BRASIL. Secretaria de Políticas das Mulheres. Política Nacional de Enfrentamento à Violência contra as Mulheres. Brasília, 2005.

BRASIL. II Plano Nacional de Políticas para Mulheres. Brasília, 2010. FUNDAÇÃO PERSEU ABRAMO. Violência contra a Mulher na esfera pública e privada: Relatório de Pesquisa. 2010.

IPEA. Igualdade de gênero. Políticas sociais - acompanhamento e análise, Brasília, 14 fev. 2007, p.227-248. Disponível em: <http:// www.ipea.gov.br/portal/images/stories/PDFs/politicas_sociais/ bps14_completo.pdf>. Acesso em: 14 fev. 2007.

LÜCK, H. Pedagogia Interdisciplinar: fundamentos teórico-metodológicos. 10. ed. Petrópolis: Vozes, 2002.

OBSERVATÓRIO LEI MARIA DA PENHA. Projeto: Construção e Implementação do Observatório da Lei 11.340/2006 - Lei Maria da Penha. Porto Alegre (RS), 2009.

OBSERVATÓRIO LEI MARIA DA PENHA. Identificando entraves na articulação dos serviços de atendimento às mulheres vítimas de violência doméstica e familiar em cinco capitais: Relatório Final. Porto Alegre (RS), 2011. 
PINTO, Carla. Empowerment: uma prática de Serviço Social. In: BARATA, O. (Coord.). Política Social. Lisboa: ISCSP, 1988.

PNUD. Programa das Nações Unidas para o Desenvolvimento. Relatório do desenvolvimento humano 2002. Aprofundar a democracia num mundo fragmentado. Disponível em: <http://www. crescer.org/glossario/doc/143.pdf>. Acesso em: 1 ago. 2012.

RIO GRANDE DO SUL (Estado). Coordenadoria Estadual da MuIher. Plano RS Mulher. Porto Alegre, 2010.

SAFFIOTI, Heleieth. Violência doméstica ou a lógica do galinheiro. In: KUPSTAS, Marcia (Org.). Violência em debate. São Paulo: Moderna, 1997.

STREY, Marlene Neves. Violência de Gênero: uma questão complexa e interminável. In: STREY, Marlene Neves; AZAMBUJA, Mariana P. Ruwer; JAEGER, Fernanda Pires (Org.). Violência, gênero e políticas públicas. Porto Alegre: Edipucrs, 2004. 